\title{
A reforma do ensino médio nos anos de 1990: o parto da montanha e as novas perspectivas*
}

\author{
Dagmar M. L. Zibas \\ Fundação Carlos Chagas
}

\section{Introdução}

Os anos finais da década de 1990 e os anos iniciais do novo século reservaram ao ensino médio uma grande turbulência estrutural e conceitual, sem que, no entanto, fossem delineadas perspectivas concretas de melhoria da qualidade. Assim, a intensidade do movimento reformista no nível oficial e a precariedade material e política dos processos de implementação parecem equiparar a reforma dos anos de 1990 à pretensiosa, contraditória, tumultuada e breve reforma de 1971, que instituiu a profissionalização compulsória no então denominado ensino de $2^{\circ}$ grau.

É evidente que, para caracterizar adequadamente a reforma em questão, é necessário compreendê-la no quadro mais amplo da reforma educacional, bem como no bojo da reestruturação do Estado e da constituição de novos modos de acumulação do capital. Todavia, esses aspectos fundamentais não serão aqui

* Versão atualizada de trabalho apresentado na $26^{\text {a }}$ Reunião Anual da ANPEd, realizada de 5 a 8 de outubro de 2003, em Poços de Caldas (MG) tratados, principalmente por já haver extensa e sólida literatura a respeito. Tampouco será discutida a desarticulação entre o ensino médio e o ensino técnicoprofissional, promovida ao final do Governo Fernando Henrique Cardoso, mesmo porque tal desarticulação já foi parcialmente revertida. ${ }^{1}$ Outros aspectos das políticas dos anos de 1990 que atingiram o conjunto da educação básica também estarão ausentes desta análise, uma vez que o objetivo aqui é enfocar a reforma dos anos de 1990, naquilo que foi especificamente dirigido ao chamado ensino médio regular. Assim, o foco deste trabalho estará voltado para alguns ângulos da ambiciosa reforma curricular que, a partir da resolução no 3/98 do Conselho Nacional de Educação, constituiu o fulcro das pretendidas transformações na escola média.

A favor da reforma curricular deve-se registrar que o contexto da virada do século justificava (e ainda justifica) um profundo repensar do currículo do

${ }^{1}$ A revogação parcial dessa desarticulação, por meio do decreto $n^{\circ} 5.154$, de 23 de julho de 2004, merece um aprofundamento que não é o propósito deste texto. 
ensino médio, em vista, principalmente, das seguintes constatações e análises:

\section{a) Explosão da demanda por matrículas}

A pressão da demanda sobre o ensino médio aumentou de forma excepcional. Basta notar que em 1994 eram pouco mais de 5 milhões de matrículas. Em 2000 estavam registrados mais de 8 milhões de alunos. Ou seja, em seis anos houve um acréscimo de mais de 50\% de inscritos. Em 2003, mais de 9 milhões de jovens freqüentavam o ensino médio. ${ }^{2}$ Esses números indicam maior democratização do acesso, com a matrícula de jovens cujos pais, em grande maioria, tiveram nenhuma ou muito pouca escolarização. Em contrapartida, a maior heterogeneidade do alunado reforça a crítica a conteúdos enciclopédicos e descontextualizados, bem como a métodos tradicionais de ensino, exigindo-se uma reforma que torne a escola média realmente inclusiva.

\section{b) Requisitos do novo contexto produtivo}

Desde mais de uma década, há um discurso muito difundido em toda a sociedade que defende a necessidade de formação dos jovens com base em novos conhecimentos e competências, de modo que possam interagir com as profundas mudanças socioeconômicas, tecnológicas e culturais da contemporaneidade. Em que pese o grande volume de críticas bem fundamentadas que esse discurso oficial e oficioso tem recebido de educadores - algumas das quais serão tratadas mais adiante -, é preciso reconhecer que as necessidades de desenvolvimento social e econômico são muito concretas e que - embora as relações macroestruturais componham o núcleo dessas rápidas mudanças - a formação da juventude para enfrentar a nova realidade impõe-se como um desafio

${ }^{2}$ Fonte: Ministério da Educação (MEC), Instituto Nacional de Estudos e Pesquisas Educacionais Anísio Teixeira (INEP), <www.mec.gov.br〉. Acesso em junho de 2004. muito objetivo, sempre resguardada a compreensão de que tal formação deve ser muito mais ampla e profunda do que aquela demandada pela produção.

\section{c) Exigência de desenvolvimento de conhecimentos e valores para a construção de uma cidadania democrática}

O fato de que a escola não pode desconhecer as exigências da produção - como mencionado anteriormente - não pode significar, evidentemente, que se deva submeter passivamente à racionalidade econômica vigente. Ao contrário, a par da inevitável instrumentação dos jovens, para que sobrevivam no mundo real, torna-se fundamental que a escola ensine a "leitura desse mundo", ou, em outras palavras, que desenvolva a cidadania democrática, aqui entendida como a compreensão histórica das relações estruturantes do mundo econômico e social, de forma que a sociedade seja percebida como passível de ser transformada. Este é, sem dúvida, o elemento mais complexo das demandas sobre a escola, pois há divergentes posicionamentos sobre as possibilidades de que a escola - em vista de suas determinações históricas e sociais - possa exercer esse papel. Entretanto, o atual contexto - de aumento das desigualdades, de anomia social generalizada, de violência social, de crise de valores e de colapso ou perda de importância dos veículos tradicionais de socialização da juventude pode facilitar a compreensão do currículo desse ângulo político-pedagógico.

\section{d) Exigência de aproximação entre currículo e cultura juvenil}

Os professores têm, em geral, grande dificuldade de aproximar-se da cultura adolescente. Esse distanciamento afunila a cultura da escola, empobrece as trocas entre os sujeitos do mundo escolar e converte, muitas vezes, o conteúdo das disciplinas em elemento aversivo aos alunos. Além disso, está muito evidente que, mesmo para aqueles jovens que conseguem terminar o ensino médio, o baixo cresci- 
mento econômico do país e, em alguma proporção, as novas estruturas produtivas já automatizadas tornam as oportunidades de trabalho muito escassas. Essa falta de perspectiva tende a induzir o estudante a desinteressar-se pelas atividades escolares e a incentivar comportamentos agressivos. Na verdade, o jovem vive um paradoxo: de um lado, sabe que precisa do certificado do ensino médio para a obtenção de um emprego formal; por outro, também percebe que, mesmo que obtenha o certificado, suas chances no mercado de trabalho são muito pequenas. Nesse quadro, a sensibilidade de professores à cultura juvenil (por exemplo, à música, à dança, às “tribos", à moda) torna-se uma exigência pedagógica como meio de enriquecimento dos conteúdos disciplinares e forma de construir uma identificação positiva do aluno em relação à escola. Nessa perspectiva, no entanto, a aproximação aqui discutida não deve significar a simplificação do currículo ou mero instrumento de sedução dos jovens para facilitar o trabalho docente.

Embora essas indicações de necessidade de reforma curricular já pudessem ser identificadas há muito tempo, o parecer no 15/98 da Câmara da Educação Básica do Conselho Nacional de Educação (que fundamentou a resolução no 3/98 do mesmo órgão), propondo as novas Diretrizes Curriculares Nacionais para o Ensino Médio (DCNEM) causou um certo grau de perplexidade nas redes de ensino e na academia. $\mathrm{O}$ impacto inicial do projeto decorria, principalmente, de sua clara pretensão de "refundar" a escola média, uma vez que veiculava um conjunto de princípios ainda inéditos no processo de implantação da Lei de Diretrizes e Bases de 1996. De fato, a indicação da interdisciplinaridade e da organização do currículo por áreas de conhecimento, da contextualização dos conteúdos, a ênfase na aprendizagem e no protagonismo do aluno, deslocando o professor do centro do processo e a insistência no desenvolvimento de competências, não na transmissão de conhecimentos, constituíram um conjunto de diretrizes que objetivava mudar radicalmente o perfil da escola média.

A discussão do parecer $n^{\circ}$ 15/98 em diversas audiências públicas revelou que sua estrutura teórica muito bem articulada e seu estilo aparentemente sem arestas não eram capazes de elidir a veiculação de conceitos polissêmicos, cuja significação no contexto, entretanto, era de difícil apreensão. Em certo sentido, o documento criou o que Veríssimo, em 2002 (apud Frigotto \& Ciavatta, s.d.), chamou de "inferno semântico", segundo o qual os significados partilhados por uma literatura progressista são sutilmente enviesados (ou tornados "híbridos", como aponta Lopes 2002a), procurando legitimação ao embaralhar os campos político-ideológicos, confundindo a crítica.

Nesse cenário, a exegese dos fundamentos da reforma demandou significativo esforço teórico. Como consequiência, ao longo do tempo foi constituindo-se um corpo crítico bastante sólido em seu conjunto - formado tanto de análises pontuais quanto de outras mais estruturais -, o que pode permitir hoje a superação da reforma de 1998 e a construção de novas alternativas.

\section{A repercussão na academia}

O trabalho de Machado (1998) é um exemplo das análises que procuraram desbastar o "inferno semântico" das diretrizes curriculares. Essa autora, entre outros aspectos, discute o desenvolvimento da subjetividade, o qual, segundo o documento, seria a base para toda a formação derivado da estética da sensibilidade. Tal estética estaria significada pela criatividade, pelo belo, pela sutileza e pela delicadeza. Machado põe a nu o viés ideológico dessa construção teórica quando, entre outros argumentos, reafirma que a sociedade atual tem "acentuado as clivagens sociais, mediadas por interesses contraditórios e conflitos de toda sorte, fazendo com que os entendimentos do que seja criatividade, beleza, sutileza e delicadeza sejam não somente diferentes, como até contraditórios" (p. 88).

A recomendação das DCNEM - de que o currículo seja construído de forma a prever estratégias que, entre outros objetivos, ajudem o estudante a "suportar a inquietação" - também foi consistentemente criticada (Martins, 2000). Aqui a questão é: o que 
inquieta o jovem contemporâneo? Sem dúvida, o desemprego, os baixos salários, a violência, a corrupção... Essa leitura indica que a acomodação (não a participação em processos transformadores) pode ser um dos desdobramentos do currículo recomendado.

Lopes (2002a) enfocou um dos princípios centrais da reforma curricular - a contextualização - para, em uma análise rigorosa, identificar o caráter híbrido do conceito como tratado nos documentos do MEC. O hibridismo descrito exemplifica bem os vieses do discurso oficial, pois, por um lado, pode-se interpretar o conceito como próximo a vertentes legitimadas por educadores críticos. Por outro lado, no entanto, a contextualização, tal como divulgada oficialmente, ignora o âmbito da cultura mais ampla, restringindose à "perspectiva de formação de performances que serão validadas nos exames centralizados e nos processos de trabalho" (p. 396).

A questão da cidadania também é ambígua nas diretrizes que apenas a qualificam como "de qualidade nova". Pode-se ver nessa qualificação uma aproximação do conceito definido em Mello (1993). Essa autora (relatora do parecer $n^{\circ} 15 / 98$ ) prega a despolitização das demandas sociais, defendendo o ponto de vista de que a atuação "moderna" do cidadão deveria ter uma orientação pragmática e técnica. Tal concepção de cidadania já foi criticada, argumentado-se que a despolitização da ação coletiva é fatal para a democracia (Guehenno, 1994).

Em contrapartida, os conceitos de interdisciplinaridade e da organização do currículo por áreas de conhecimento, veiculados pelas diretrizes, encontraram menor resistência nos meios acadêmicos. Na verdade, a idéia de diminuir a fragmentação do conteúdo escolar sempre foi cara aos pedagogos. Esse aspecto da reforma pareceu, para alguns, ter vindo ao encontro dessa perspectiva. Kuenzer (2000), por exemplo, discutindo esses aspectos, conclui que tal tratamento teórico-metodológico, "fornecerá o necessário suporte à participação na vida social e produtiva" (p. 28). No entanto, Lopes (2002b) chama a atenção para o fato de que a potencialidade crítica da interdisciplinaridade encontra-se minimizada na reforma em ques- tão, a partir de sua hibridização com matrizes teóricas diversas, principalmente com discursos associados ao currículo por competências, o qual, por sua vez, está em sintonia com as teorias da eficiência social, com ênfase na construção e validação de determinadas performances demandadas principalmente pela produção, o que, sem dúvida, fortalece perspectivas ideológicas conservadoras.

Outro alerta quanto à prescrição da interdisciplinaridade veio em relação à formação docente. $\mathrm{O}$ parecer da ANPEd (1997) sobre o Plano Nacional de Educação advertia que a interdisciplinaridade do método não pode ser confundida com a polivalência docente - polivalência que, para o ensino médio, só pode significar empobrecimento da transmissão do conhecimento.

Todavia, foi o eixo do desenvolvimento das competências, nas diretrizes curriculares, que mais concentrou a atenção dos especialistas. As primeiras críticas apontaram a origem do conceito no modelo de competências desenvolvido na área empresarial para a seleção e treinamento de trabalhadores, destacando os seguintes desdobramentos desse modelo nas relações capital-trabalho:

a) enfraquecimento da associação dos trabalhadores, incentivando a competição entre eles e favorecendo as negociações trabalhistas individualizadas;

b) a responsabilização de cada trabalhador por suas possibilidades de empregar-se e manterse empregado, minimizando-se as condições macroestruturais determinantes dos níveis de emprego e desemprego, estabelecendo, dessa forma, novos conformismos sociais, ou seja, tornando naturais condições perversas do mercado, como a incerteza do futuro profissional e a precarização do trabalho.

O aprofundamento da crítica ao modelo de competências, da forma como incorporada às diretrizes curriculares, apontou a isonomia entre o modelo criado no âmbito empresarial e aquele introduzido nos docu- 
mentos oficiais. Machado (2002), por exemplo, discute o processo de institucionalização da lógica das competências no Brasil e conclui, entre outros aspectos, que a intenção que sustenta tal processo é a de "fazer mudanças nas práticas sociais [...] especialmente nas esferas do trabalho e da educação, pretendendo também ocultar o caráter de tais mudanças, que só aparentemente é neutro em relação às classes sociais e às oportunidades sociais e educacionais" (p. 109).

Como mencionado anteriormente ao se discutir as críticas à interdisciplinaridade, afirma-se que o modelo de competência tem sido associado também a teorias do eficientismo social, em vista de sua ênfase na avaliação de comportamentos terminais, principalmente daqueles demandados pela produção, o que o torna veículo de uma ideologia conservadora (Lopes, 2002b). Adicionalmente, o aporte psicológico da pedagogia das competências foi criticado por visar à construção do novo profissionalismo, em particular de esquemas cognitivos e socioafetivos que possibilitem a adaptação dos sujeitos às situações novas de trabalho e não-trabalho. Nesse quadro, há excessiva ênfase nos aspectos subjetivos dos alunos, negligenciando-se o conjunto de determinações históricas e sociais que incidem sobre o processo educativo ( $\mathrm{Ra}-$ mos, s.d.).

O breve levantamento de algumas das análises sobre a reforma curricular do ensino médio, aqui realizado, embora constituindo apenas uma pequena amostra do corpo crítico construído, já delineia a dimensão e a profundidade dessa produção acadêmica. Quanto ao impacto da reforma no cotidiano escolar, os estudiosos tendem a reconhecer que há sempre uma discrepância entre os fins enunciados das políticas e a prática nas escolas, principalmente por uma relativa autonomia de que gozam os sujeitos sociais dentro de cada instituição escolar. A esse respeito, entretanto, há a advertência de que não convém menosprezar o poder do currículo oficial sobre o cotidiano das escolas, principalmente porque os recursos são distribuídos na proporção da adesão às mudanças e porque o novo código oficial se apropria, ressignificando-os, de princípios curriculares legitimados pelo campo educacional (Lopes, 2002a).

\section{A repercussão nas escolas}

Já aprendemos que toda política curricular é constituída de propostas e práticas curriculares que se interpenetram, não sendo possível separá-las e desconsiderá-las em suas inter-relações (Lopes, 2004). Sabemos, também, que as escolas são capazes de interagir com as inovações, somente na medida em que lhes permita sua configuração histórica, e que tal configuração, para se mover, necessita - entre outras condições - de tempo (Ezpeleta, 2002). Assim, compreende-se que é ainda cedo para avaliar as interações entre as propostas curriculares oficiais e a prática escolar. No entanto, o acompanhamento da fase inicial do encontro entre as diretrizes oficiais e os sujeitos da cena escolar tem sido útil para dar pistas sobre possíveis desdobramentos.

Foi essa a motivação da pesquisa que enfocou 18 escolas em três estados (Zibas \& Krawczyk, 2005), ${ }^{3}$ e acompanhou, entre 2001 e 2004, a implantação da reforma do ensino médio, principalmente no que diz respeito ao currículo. Até 2002, foi registrado que os professores entrevistados relacionavam a reforma do ensino médio a somente três aspectos: a) algumas melhorias nas condições físicas da escola; b) novas formas de avaliação (avaliação em processo ou progressão continuada); c) diminuição de horasaula de algumas disciplinas (para implantação da parte diversificada do currículo).

O primeiro aspecto, (a), embora importante, não pode ser considerado o principal eixo da reforma. Quanto ao segundo, (b), a avaliação faz parte de um processo generalizado adotado, principalmente, para a melhoria do fluxo do sistema e decorrendo, segundo alguns autores (por exemplo, Demo, 1998), de

${ }^{3}$ Pesquisa financiada pela Fundação Ford, desenvolvida nos estados do Ceará, Pernambuco e Paraná, cujo relatório final foi publicado em 2005. 
má interpretação da Lei de Diretrizes e Bases da Educação Nacional. Tiramonti (2001), analisando o mesmo processo na Argentina, considera que foi implantada a "promoção automática" e considera este dispositivo em contraponto à avaliação externa, também generalizada em todo o continente. Conclui que a aparente contradição entre os dois processos deve ser referida à mudança no papel do Estado, que, por um lado, deve constituir-se em órgão para a vigilância e disciplinamento dos agentes do sistema, para o que a avaliação externa é adequada, e, por outro, deve garantir a contenção e o controle dos necessitados, para o que a permanência desses alunos na escola, através da promoção automática, é de grande importância.

No que diz respeito ao Brasil, os dados da pesquisa mencionada indicam que as escolas não têm condições mínimas - materiais, administrativas e pedagógicas - de recuperar satisfatoriamente a aprendizagem de alunos que devem continuar o curso, embora retidos em até três disciplinas. Os jovens, em geral, também não têm condições de freqüentar a escola em horários alternativos, de forma a reconstruir as aprendizagens avaliadas como insuficientes. Nesse quadro, instalam-se meras formalidades que mascaram a simples promoção automática. Todo o processo é agudamente criticado por todos os profissionais entrevistados nas escolas. Embora nessas críticas possam ser encontradas motivações relativas à perda do poder docente que a avaliação tradicional proporcionava, os professores esgrimem, em geral, argumentos importantes quanto à falta de estrutura mínima para a implantação de um tipo de avaliação que exige acompanhamento individual do progresso do aluno. $^{4}$

No tocante à implantação da parte diversificada do currículo, embora se trate de elemento essencial da reforma e se pulverize, em cada rede estadual, em centenas de nomes de "disciplinas" (ou pseudodisci-

${ }^{4}$ Foram encontrados casos de professores que atendem quase mil alunos em duas ou três escolas. plinas), não se notou, no ambiente escolar, qualquer impacto inovador. Aliás, ao tratar do tema, os professores entrevistados apenas destacavam a diminuição de determinadas cargas horárias e, em geral, defendiam o "malabarismo" administrativo necessário para acomodar os docentes que perdiam horas-aula com a introdução das novas diretrizes curriculares (Zibas \& Krawczyk, 2005). ${ }^{5}$ Assim, nas escolas pesquisadas, foi possível atribuir a "opacidade" da inovação formalmente introduzida ao fato de que a pretendida diversidade curricular se implementou de modo a apenas atender interesses dos docentes, sem cumprir a função prevista de suprir necessidades específicas do alunado. Em alguns casos, nos quais se tentou atender as necessidades dos estudantes (por exemplo, por aulas de informática), não havia recursos materiais e/ ou disponibilidade de especialistas para a implementação.

O estudo citado passou a registrar que, a partir de 2003, a reforma começava a ser relacionada, nas escolas, ao desenvolvimento de projetos. Esse mesmo dado foi anotado pela pesquisa que focalizou, nos anos de 2002 e 2003, cinco escolas nos estados de São Paulo e Ceará (Zibas, Ferretti \& Tartuce, 2004). Com o rótulo de "projetos", todos os princípios da reforma curricular (a interdisciplinaridade e a organização do currículo por áreas do conhecimento, o desenvolvimento de competências, a ênfase no protagonismo do aluno e na contextualização dos conteúdos) foram diluídos, eximindo-se os professores e os grupos gestores de maior reflexão sobre esses conceitos.

Essa omissão dos profissionais e o processo de "simplificação" da reforma podem ser analisados como resultado de um grande distanciamento entre os propósitos oficiais e as condições objetivas do trabalho nas instituições. Também nos remete à crítica de Tiramonti (2001), que, estudando a reforma ar-

${ }^{5}$ Em uma das escolas do Ceará, o "malabarismo" de acomodação traduziu-se na inclusão de aulas de latim, de forma a não prejudicar o professor de História, que havia perdido horas-aula. 
gentina, conclui que ela está baseada em uma racionalidade técnica que se fecha sobre si mesma e não considera as restrições materiais, institucionais e políticas que atravessam o conjunto da sociedade e, especificamente, os sistemas educacionais.

De fato, as duas pesquisas mencionadas coletaram diversos indícios de que os exigentes princípios da reforma curricular passam ao largo do cotidiano escolar. Por exemplo, o trabalho coletivo dos docentes - recurso indispensável para implantação da interdisciplinaridade - era raro. Quando havia possibilidade de reuniões de professores em alguns sábados por ano, como no caso de escolas do Ceará, os assuntos administrativos dominavam o espaço e os aspectos pedagógicos eram tratados de maneira tradicional, não se registrando influência específica da reforma. Ainda, nessas reuniões, havia muitas faltas de docentes, que devem conciliar a convocação aos sábados com outros compromissos assumidos, em vista de sua vinculação a dois ou três diferentes estabelecimentos de ensino. Essa conhecida característica da função docente - de "taylorização" de seus espaços e tempos (Kuenzer, 2002) - impede até mesmo que professores da mesma área se comuniquem no dia-a-dia escolar. Muitos entrevistados, quando questionados sobre suas relações profissionais com colegas, citaram os intervalos de aula e os cruzamentos em horários de saída ou entrada como únicos espaços usados para tal fim.

Abramovay e Castro (2003), em pesquisa patrocinada pela Organização das Nações Unidas para a Educação, a Ciência e a Cultura (UNESCO) e pelo MEC, focalizando 673 escolas em 13 estados brasileiros, destacam a falta de conhecimento e de compreensão dos professores entrevistados quanto aos objetivos da reforma e destacam que "a falta de momentos planejados e sistematizados para estudos e discussão com docentes e equipes pedagógicas das escolas sobre os princípios e pressupostos da nova concepção [...] colaboram para agravar essa situação" (p. 248).

Nesse contexto, a realização de "projetos" dáse, em grande parte, por indução das secretarias de estado, organizações não-governamentais ou universidades. Um exemplo é o projeto Amor à Vida, financiado pelo Fundo das Nações Unidas par a Infância (UNICEF) e pelo Fundo de População das Nações Unidas (UNFPA), introduzido nas escolas do Ceará pela Secretaria do Trabalho e Ação Social. No entanto, projetos de origem extra-institucional dificilmente são integrados organicamente ao currículo. $\mathrm{O}$ que se verifica é que as atividades são pontuais, intermitentes, envolvendo poucos alunos e professores. Os projetos registrados como de iniciativa dos docentes também envolviam, em geral, apenas um pequeno grupo de professores e alunos, sendo considerados, na maior parte das vezes, atividades paralelas ao currículo (Zibas, Ferretti \& Tartuce, 2004). Mesmo propostas muito bem construídas do ponto de vista teóricometodológico, como algumas promovidas por universidades em colaboração com as secretarias de educação, não têm, em geral, conseguido romper a barreira da precariedade institucional. O caso relatado por Kuenzer (2002) é exemplar nesse sentido.

O regime de trabalho docente, que dificulta as reuniões pedagógicas, também se contrapõe ao objetivo das DCNEM quanto à construção de escolas com forte identidade. Diante de um corpo docente que corre diariamente entre dois ou três estabelecimentos, sem tempo para fazer-se conhecer - além dos estritos limites do quadro negro e do giz - e sem disponibilidade para aproximar-se de seus alunos e da comunidade, a decantada "construção de forte identidade da escola" tende a tornar-se utópica. A constante transferência e a intensa mobilidade de professores e diretores entre as escolas - até mesmo em pleno ano letivo (como foi registrado nas escolas paulistas por Zibas, Ferretti \& Tartuce - 2004) - apenas aprofunda as contradições entre os objetivos propostos e a realidade dos sistemas educativos.

Além disso, a capacitação docente, mesmo quando fisicamente bem estruturada - como no caso do Paraná e o seu tão divulgado centro de formação de Faxinal do Céu - não mostrou ser instrumento de difusão da reforma nas escolas focalizadas pelos estudos de Zibas e Krawczyk (2005) e Zibas, Ferretti e 
Tartuce (2004), já referidos. A rarefação e fragmentação dos cursos, a falta de sintonia entre as reais necessidades de formação do conjunto de profissionais de cada escola e os cursos oferecidos, a acomodação dos docentes, sua alta rotatividade por diferentes escolas da rede e a pulverização dos professores envolvidos, que não se comunicam com seus pares dentro de suas instituições, limitam extremamente essa iniciativa dos governos estaduais, mesmo daqueles politicamente muito afinados com as reformas dos anos de 1990 e pioneiros em sua implantação, como São Paulo, Paraná e Ceará. ${ }^{6}$

Ainda, em se tratando de uma reforma curricular que pretendeu "refundar" a escola média, caracterizando-a como "escola jovem" e propondo ações pedagógicas diferenciadas, integradas e abrangentes, a reestruturação física dos estabelecimentos e o fornecimento de equipamentos adequados - como laboratórios, bibliotecas e outros espaços pedagógicos parecem imprescindíveis. De fato, como se sabe, através do projeto Escola Jovem do Governo Federal, empréstimos internacionais foram dirigidos, entre outros objetivos, para a melhoria da estrutura física e pedagógica das escolas médias.

Entretanto, diversos levantamentos feitos mostram que as deficiências materiais e a má conservação ou a má utilização dos equipamentos continuam. Por exemplo, com relação aos laboratórios de informática, os dois estudos mencionados registraram que os equipamentos, na maioria dos casos, são muito reduzidos (muitas vezes só disponíveis nas salas da administração e dos professores) e não contam com manutenção. No Paraná, onde há escolas com maior número de computadores, foram encontradas salas de informática fechadas, totalmente sem uso, por falta de instrutores e de conhecimento, de tempo ou de interesse dos professores no manejo dos instrumentos. A pesquisa de Abramovay e Castro (2003) também concluiu que, apesar de diferenças regionais e

6 No caso do Paraná, refiro-me aqui, principalmente, à gestão estadual que terminou em 2002. entre escolas, a exclusão digital por falta de equipamento, uso limitado ou falta de manutenção é uma constante. Em São Paulo, por exemplo, somente $16,9 \%$ dos alunos das escolas públicas contatados informaram usar computador na escola. Conforme estas autoras, em sua investigação, o destaque positivo foi o do Paraná, onde, no entanto, menos da metade dos alunos pesquisados afirmaram usar laboratórios de informática.

Os laboratórios de ciências também representam um elo frágil na implantação da reforma curricular. As três pesquisas mencionadas constataram que os laboratórios, quando existem, são somente esporadicamente usados, em vista da falta de material ou de tempo do professor para montar o equipamento e preparar as aulas práticas.

Quanto às bibliotecas escolares, embora possuam equipamento mais bem distribuídos e em processo de melhoramento, são ainda muito insuficientes e usadas de modo muito restrito. Foi essa a constatação das três pesquisas já referidas.

As pobres condições técnicas, físicas e profissionais do trabalho docente evidentemente constroem também condições políticas adversas para a implantação da reforma oficial. Ou seja, a precariedade estrutural do sistema tende a aumentar as resistências dos professores a qualquer inovação proposta pelos órgãos centrais. Essa realidade chega a apresentar dificuldades até para pesquisadores. Um exemplo deuse em junho de 2003, em escolas do Ceará, quando se procurava entrevistar professores sobre a reforma e o único tema que interessava aos depoentes era o atraso que se registrava no pagamento dos salários. Nessa mesma época, diversas entrevistas foram canceladas em vista do estado de greve do magistério.

Todo esse quadro dá razão a Kuenzer (2002) quando afirma que "a reforma do ensino médio não é [ou não foi] para valer" (p. 327). Professores entrevistados por Abramovay e Castro (2003) também mostraram ter clara visão da distância entre a reforma oficial e a realidade. Segundo eles, "Não adianta colocar uma lei [as diretrizes] e não ter condições de colocar essa lei em prática" (p. 269). E ainda: "Nós 
somos uma classe de 'professor-táxi': trabalha aqui e trabalha em outras escolas. De repente, ele [o processo de reforma] passa despercebido" (p. 271). Não se trataria, pois, de discutir se o cotidiano escolar tem ou não força para construir-se a despeito das orientações oficiais (Lopes, 2002b), mas, sim, de constatar que as diretrizes oficiais não têm condições objetivas de repercutir no dia-a-dia da escola.

Esse abismo entre a sofisticação do discurso oficial e a rudeza do cotidiano da escola média, pública, precisamente quando esse espaço se abre para as camadas populares, coloca-se a questão: por que isso se dá? Uma resposta pessimista, mas bem fundamentada, é dada por Tiramonti (2001, p. 17):

La diferenciación del sistema parece haver proporcionado finalmente a la educación un mecanismo de selección de la población que permite resguardar a la cúspide de la permanente presión de los sectores emergentes em pro de más educación. La diferenciación permite abrir todos los niveles del sistema sin que por esto se amenacen los límites impuestos por la reproducción de las diferencias sociales.

De todo modo, no bojo do grande movimento reformista, a falta de aprendizagem dos novos contigentes de alunos que chegam à escola, principalmente ao nível do ensino médio, já exigiu dos antigos mentores das reformas algumas explicações. Nesse cenário, diversos argumentos acabam associando, de maneira "natural", a pobreza dos alunos aos baixos escores nas provas de rendimento. Tedesco (2001a), ao reconhecer alguns aspectos deletérios das reformas educacionais na América Latina, introduz o conceito de "educabilidade", por meio do qual explica que a condição de pobreza elimina as condições essenciais para a aprendizagem. Esse argumento já serviu, em passado recente, de guarda-chuva protetor às autoridades educacionais do governo anterior, as quais, diante da piora dos resultados do Sistema de Avaliação da Educação Básica (SAEB) de 2001 e do Exame Nacional do Ensino Médio (ENEM) de 2002, mencionaram, no primeiro caso, a abertura da escola a alunos mais pobres e, no segundo, a eliminação das taxas de acesso ao exame, com a conseqüente participação dos mais pobres, como causas dos maus resultados registrados. ${ }^{7}$

\section{0 parto da montanha: há alternativas?}

É preciso reconhecer que o discurso oficial dos anos de 1990 contido nos documentos legais e difundido em numerosas publicações, no âmbito federal e no dos estados e toda a consistente produção crítica acadêmica sobre a reforma do ensino médio, principalmente sobre a reforma curricular, compõem dois pólos de um conjunto sólido, cujas dimensões pedagógicas, sociológicas, filosóficas e politíco-ideológicas, no entanto, nos melhores casos, apenas arranham o cotidiano escolar.

No momento em que se abrem novas perspectivas políticas para a reconsideração do ensino médio, parece importante insistir na discussão do significado do currículo para a escola média. Nesse contexto, convém considerar-se que o conjunto de críticas elaboradas aponta a existência de elementos da reforma curricular de 1998 que, devidamente "recontextualizados", ou reinscritos em uma proposta abrangente, democrática e progressista, podem ajudar a construir a mandatória dimensão inclusiva do ensino médio.

O primeiro conceito a ser recuperado parece ser o de "escola jovem". Embora a histórica indefinição do ensino médio tenha ficado menor quando a Lei de Diretrizes e Bases de 1996 definiu que o ensino fundamental e o ensino médio devem constituir uma seqüência educacional integrada, restou, no entanto, caracterizar melhor o nível médio, diferenciando-o do fundamental. A classificação do ensino médio como escola de jovens pode cumprir este papel - neste caso, a preposição atributiva possessiva é importante -, em que se pese a dificuldade de definir-se com precisão o conceito sociocultural de juventude. Sabe-se que o

${ }^{7}$ Folha de S.Paulo, São Paulo, 6 de dezembro de 2002, p. C.1, e 13 de novembro de 2002, p. C.1. 
maior risco da difusão dessa categoria, como de outras de forte raiz cultural, é o da diluição das clivagens de classe, em uma visão que tende a homogeneizar opostos e elidir conflitos. No entanto, também é preciso reconhecer que os jovens, distribuídos por todo o espectro social, compartilham diversas características comuns que podem e devem ser valorizadas pela escola, como forma de dinamizar e enriquecer a cultura enraizada intramuros, para que essa cultura se abra às expectativas e aos interesses dos alunos. Nesse quadro, a caracterização, principalmente do ensino noturno, como escola do jovem trabalhador, pode evitar reducionismos economicistas, sociológicos ou culturalistas, bem como enfoques simplistas e unidirecionais.

O princípio da contextualização, veiculado pela reforma, é o de recuperação inevitável, uma vez que tem larga tradição junto a educadores progressistas. A “contaminação" desse conceito por princípios do eficientismo social (Lopes, 2002a) pode ser revertida por meio de ampla discussão que recoloque a necessidade de que o ensino dos conteúdos escolares valorize os conhecimentos prévios dos alunos e os saberes cotidianos, principalmente como meio de construir-se uma compreensão menos massificada da vida social.

Adicionalmente, vimos que a interdisciplinaridade e a organização do currículo por áreas do conhecimento, como constante nas Diretrizes Curriculares, receberam apoio de muitos especialistas, que viram nesse enfoque metodológico o necessário suporte à participação do jovem na vida social e produtiva (Kuenzer, 2000, 2002). Essa perspectiva otimista, entretanto, precisa ser revista à luz de diversas críticas, principalmente daquelas que chamam a atenção para a necessidade de melhor definição do conceito. Já vimos que Lopes (2002b) alerta sobre o hibridismo do discurso oficial que divulgou a interdisciplinaridade.

Além disso, é preciso atentar para outros limites da proposta. Em que se pesem as críticas ao enfoque disciplinar do currículo, segundo as quais as disciplinas controlam e reduzem os possíveis discursos sobre os objetivos sociais da educação (Macedo \& Lopes, 2002), diversos autores chamam a atenção para o fato de que os imprescindíveis projetos interdisciplinares não podem apagar as fronteiras entre as disciplinas escolares, que devem corresponder - embora recontextualizadas - às disciplinas acadêmicas, as quais têm longa tradição como unidades de sentido e permitem organizar a leitura da realidade com rigor e profundidade, mediante um conjunto de conceitos e de relações específicas que se vão modificando através de uma lógica interna (Braslavsky, 2001). Outro ponto de atenção, relacionado à necessidade de preservar as fronteiras mencionadas, diz respeito à formação docente para a interdisciplinaridade, a qual, como já discutimos, tem sido identificada com polivalência do professor do ensino médio. Tal polivalência retiraria a especificidade do ensino médio, o qual, embora imprescindivelmente articulado ao ensino fundamental, deve representar uma nova fase da vida escolar do jovem, com oportunidades reais de aprofundamento de conteúdos.

Poggi (2003) faz distinção entre currículo integrado e interdisciplinaridade. Citando J. Torres, ${ }^{8}$ essa autora define a interdisciplinaridade como a inter-relação entre vários campos de conhecimento com a finalidade de pesquisa ou solução de problemas, umas e outras vinculadas à produção de conhecimento. Por outro lado, afirma que a integração curricular não necessariamente significa supressão das disciplinas. Chama a atenção, também, para o risco de considerar-se que o currículo especializado e o integrado constituam, respectivamente, exemplos paradigmáticos de má e boa prática curricular. Ainda, ao discutir a necessidade de um novo currículo para a escola média argentina, argumenta que um novo modo de abordar as relações entre escola e conhecimento, de forma a superar a falta de significado dos conteúdos escolares, deve considerar o currículo integrado como um ponto de chegada, não um ponto de partida da reforma. Essa estratégia parece imprescindível para não se confrontar de maneira improdutiva a cultura

${ }^{8}$ J. Torres (Globalización e interdisciplinaridad, 1998) apud Poggi. 
docente, abalando a identidade profissional e criando maior insegurança junto a professores, os quais foram formados nas universidades para trabalhar apenas isoladamente, dentro do campo estrito de cada disciplina. Esses argumentos de Poggi parecem muito pertinentes para o repensar da interdisciplinaridade como divulgada pelas DCNEM de 1998.

Ainda no contexto do currículo integrado, parece caber um alerta quanto ao lema "aprender a aprender", tão divulgado pela reforma. O desenvolvimento dessa inquestionável "competência" não deve significar, necessariamente, a minimização dos conteúdos disciplinares. A crítica aos conteúdos muito abrangentes só é válida para pseudoconhecimentos que não se vinculem à estrutura cognitiva dos alunos e, portanto, não tenham qualquer significado - intelectual, cultural, estético, ético, político ou prático - em suas vidas. A alegação de que a extrema velocidade da atual produção de conhecimentos os torna rapidamente obsoletos pode levar a um "relativismo educacional" muito perigoso para os filhos das camadas populares, enquanto os colégios de elite continuam insistindo para que os jovens da classe média mergulhem mais fundo no corpo de conhecimentos historicamente acumulados, o que apenas confirmará sua posição de classe.

Quanto ao "modelo de competências”, já foi aqui mencionado que o mesmo constituiu o aspecto da reforma curricular mais visada pelos críticos, que puseram a nu seus graves viéses políticos e ideológicos. Entretanto, parece que há ainda alguns pontos a serem considerados. Machado (1998) reconheceu que "a noção de competência é uma noção forte" e deve ser recuperada, mas numa perspectiva que rompa critérios que a estão orientando na atualidade: o fatalismo da disputa competitiva, a impossibilidade de evitar-se a insegurança e a incerteza, a alternativa da adaptação (p. 93). Macedo (2002), ao discutir o modelo de competência inserido nas diretrizes curriculares, argumenta que se está "diante de um paradoxo que não se pode resolver a trama política, de um lado, deixando abertos espaços para ações não-previstas, de outro, fortalecendo os mecanismos de controle" (p. 138). A autora propõe, então, que a análise dos documentos curriculares se volte para a compreensão da relação entre as restrições e as possibilidades de ação. A partir dessa mesma perspectiva analítica, já foi sugerida a consideração do desenvolvimento de competências sócio-históricas (Ibarrola \& Gallart, 1994) como possibilidade de que os jovens, aprendendo inevitavelmente a viver (como descreveram os "reformadores") em meio à insegurança, à incerteza, submetidos ao desemprego ou a ocupações precárias, possam perceber as contradições do processo e os caminhos para a construção de uma sociedade menos desigual.

Outra característica da reforma de 1998 que, parece-me, deve ser recuperada, é a da valorização dos métodos ativos. Tais métodos, que podem representar um grande auxílio para os processos de contextualização dos conteúdos, envolvem a problematização de temas da vida diária, a experimentação, a pesquisa, o estudo do meio e a elaboração/execução de projetos, e, embora não possam garantir o desenvolvimento de competências, são reconhecidamente facilitadores da mobillização e ampliação de recursos subjetivos, tais como a criatividade, a autonomia, a iniciativa, a comunicabilidade etc. $\mathrm{O}$ cuidado aqui a ser tomado é o de que a atividade e a experiência não sejam transformadas em simples "ativismo" e sobrepostas aos conteúdos. Ao contrário, a articulação equilibrada e enriquecedora entre atividade e conteúdo, de modo a desafiar o aluno a "pensar", é essencial para a aprendizagem significativa, tal como já enfatizava Saviani (1982) há mais de duas décadas.

Nessa perspectiva - evidentemente, sem qualquer ilusão de que a escola, por si só, possa produzir a igualdade - é preciso enfrentar o desafio da complexidade, se quisermos realmente caminhar na construção de uma escola média inclusiva. Isso porque, para trabalhar-se em situações de pobreza, os enfoques não podem ser simplificadores, mas sim ricos e diversificados (Tedesco, 2001b). Nesse sentido, a maior dificuldade é reconhecer que a imprescindível valorização da cultura popular não nos exime da necessidade de tornar significativo, principalmente para os fi- 
lhos das camadas populares, o conhecimento historicamente acumulado. Caso contrário, continuaremos com um sistema educacional irremediavelmente cindido entre a escola para a classe média e a escola dos pobres, em que a aprendizagem de conteúdos significativos se torna uma farsa, perpetuando-se, assim, as causas da crítica de Tiramonti (2001), já mencionadas, quanto aos novos mecanismos de seleção social, que agora permitem abrir todos os níveis de ensino às camadas populares, sem com isso ameaçar a reprodução da desigualdade.

$\mathrm{Na}$ abordagem aqui desenvolvida, fica claro que está relativizada a crítica que acentua a completa arbitrariedade e a mera manifestação de poder de qualquer corpo de conhecimento "escolarizado", aceitando-se a possibilidade da construção do conhecimento objetivo, da apreensão do real e da existência de elementos universais na cultura ocidental dominante. Nesse contexto, os caminhos para desenvolver os prérequisitos para a aprendizagem significativa são conhecidos e rejeitam a permanência de uma escola pobremente equipada (do ponto de vista material, cultural e técnico) destinada aos pobres. Ao contrário, são complexas e não pouco custosas as exigências para uma escola média inclusiva. A vinculação dos docentes a uma só instituição e a maior permanência dos jovens na escola (entendendo-se aqui por "maior permanência" maior tempo qualificado, e não mais um ano de escolaridade precária) são apenas dois dos inúmeros aspectos a serem considerados.

Considerando-se isso, as questões que se colocam são as seguintes: a nova conjuntura política é propícia a um projeto desse tipo? Ou tal projeto é inviável em vista da permanência da "mesma comunidade epistêmica" do governo anterior (Lopes, 2004)? $\mathrm{Ou}$, o que pode ser mais grave, a inviabilidade de uma escola média inclusiva é anunciada pela continuidade da mesma diretriz macroeconômica que reservou, em 2003/2004, o equivalente a quase $10 \%$ do Produto Inteno Bruto (PIB) para o pagamento dos juros da dívida externa e que, em 2005, continua restringindo drasticamente investimentos nas áreas sociais e na infra-estrutura? Infelizmente, esses temas, que ex- trapolam a especialização dos educadores, devem continuar freqüentando nossa agenda, se quisermos defender as bases necessárias para uma reforma do ensino médio "para valer".

DAGMAR M. L. ZIBAS, doutora em educação pela Universidade de São Paulo, com pós-doutorado na Universidad Nacional de Educación a Distancia, de Madri, e na Universidad Alberto Hurtado, de Santiago do Chile, é pesquisadora da Fundação Carlos Chagas. Publicou recentemente, em co-autoria com Celso Ferretti e Gisela Tartuce, "O protagonismo juvenil na literatura especializada e na reforma do ensino médio" (Cadernos de Pesquisa, São Paulo, Fundação Carlos Chagas, v. 34, no 122, maio-ago., 2004, p. 411-424). Organizou, com Márcia Ângela Aguiar e Maria Sylvia Simões Bueno, $O$ ensino médio e a reforma da educação básica (Brasília: Plano, 2002). Publicou ainda "Educational reform within a context of economic adjustment: the Brazilian case". [In: Akkari, Sultana e Gurtner (orgs.). Politiques et stratégies éducatives. Berna: Peter Lang Ed., 2001, p.45-56]. E-mail: dzibas@fcc.org.br

\section{Referências bibliográficas}

ABRAMOVAY, Miriam, CASTRO, Mary G. (coords.), (2003). Ensino médio: múltiplas vozes. Brasília: UNESCO / MEC. ANPEd (Associação Nacional de Pesquisa e Pós-Graduação em Educação), (1997). Parecer sobre a proposta do MEC para o Plano Nacional de Educação. São Paulo: ANPEd.

BRASLAVSKY, Cecília, (2001). Los procesos contemporaneos de cambio en la educación secundária en América Latina: análisis de casos en América del Sur. In: BRASLAVSKY, C. (org.). La educación secundária: cambio o immutabilidad? Buenos Aires: Santillana, p. 223-282.

DEMO, Pedro, (1998). Promoção automática e capitulação da escola. Ensaio: Avaliação e Políticas Públicas em Educação, Rio de Janeiro, v. 6, n. 19, p. 159-190, abr./jun.

EZPELETA, Justa, (2002). Innovaciones educativas. México, DF: DIE/CINVESTAV (mimeo).

FRIGOTTO, Gaudêncio, CIAVATTA, Maria, (s.d.). Educar o trabalhador cidadão produtivo ou o ser humano emancipado? São Paulo: IIEP (mimeo).

GUEHENNO, Jean-Marie (1994). O fim da democracia. São Paulo: Bertrand Brasil. 
IBARROLA, M., GALLART, M. A., (1994). Democracia y productividad: desafios de una nueva educación media en América Latina. Buenos Aires: Unesco; México: CIID-CENET. KUENZER, Acácia Z., (2002). A escola desnuda: reflexões sobre a possibilidade de construir o ensino médio para os que vivem do trabalho. In: ZIBAS, D., AGUIAR, M. A., BUENO, M. S. S. (orgs.). O ensino médio e a reforma da educação básica. Brasília: Plano, p. 299-329.

, (2000). O ensino médio agora é para a vida: entre o pretendido, o dito e o feito. Educação e Sociedade, Campinas, CEDES, v. 21, n. 70, p. 15-39, abr.

LOPES, Alice C., (2002a). Os parâmetros curriculares nacionais para o ensino médio e a submissão ao mundo produtivo. Educação e Sociedade, Campinas: CEDES, v. 23, n. 80, p. 389403 , set.

, (2002b). Parâmetros curriculares para o ensino médio: quando a integração perde seu potencial crítico. In: LOPES, A. C., MACEDO, E. (orgs.). Disciplinas e integração curricular: história e política. Rio de Janeiro: DPTA, p. 145-176.

, (2004). Políticas curriculares: continuidade ou mudança de rumos? Revista Brasileira de Educação, Rio de Janeiro: ANPEd; Campinas: Autores Associados, n. 26, p.109118.

MACEDO, Elizabeth, (2002). Currículo e competência. In: LOPES, A. L., MACEDO, E. (orgs.). Disciplinas e integração curricular: história e políticas. Rio de Janeiro: DP\&A, p.115-144.

MACEDO, E., LOPES, A. C., (2002). A estabilidade do currículo disciplinar: o caso das ciências. In: LOPES, A. C., MACEDO, E. (orgs.). Disciplinas e integração curricular: história e políticas. Rio de Janeiro: DP\&A, p. 73-94.

MACHADO, Lucília R. de Souza, (2002). A institucionalização da lógica das competências no Brasil. Pro-Posições, Campinas, Editora da Unicamp, v. 131, n. 37, p. 92-110, jan./abr. , (1998). O modelo de competências e a regulamentação da base curricular nacional e de organização do ensino médio. Trabalho e Educação, Belo Horizonte, n.4, p.79-95, ago./dez.
MARTINS, Ângela M., (2000). Diretrizes curriculares nacionais para o ensino médio: avaliação de documento. Cadernos de Pesquisa, São Paulo, Fundação Carlos Chagas, n.109, p. 67-87, mar. MELLO, Guiomar, N., (1993). Cidadania e competitividade: desafios educacionais do terceiro milênio. São Paulo: Cortez. POGGI, M. (2003). La problemática del conociomiento en la escuela secundaria. In: TENTI FANFANI, E. (org.). Educación media para todos: los desafios de la democratización del acceso. Buenos Aires: Altamira, p. 105-138.

RAMOS, Marise N., (s.d.). A pedagogia das competências e a psicologização das questões sociais. São Paulo: IIEP (mimeo).

SAVIANI, D., (1982). Escola e democracia: para além da teoria da curvatura da vara. Revista da ANDE, São Paulo, v. 1, n. 3, p. 57-64.

TEDESCO, Juan Carlos, (2001 a). Quedándonos atrás: un informe del progreso educativo en América Latina. Santiago: PREAL - Programa de Promoción de la Reforma Educativa en América Latina y el Caribe. (2001b). Introducción: los cambios en la educación secundaria y el papel de los planficiadores. In: BRASLAVSKY, C. (org.). La educación secundária: cambio o immutabilidad? Buenos Aires: Santillana, p. 11-20.

TIRAMONTI, Guillermina, (2001). Modernización educativa de los '90. Buenos Aires: Temas.

ZIBAS, D. M. L., (2001). O ensino médio na voz de alguns de seus atores. São Paulo: Fundação Carlos Chagas (Textos F.C.C., n. 20).

ZIBAS, D. M. L., FERRETTI, C., TARTUCE, G., (2004). $O$ protagonismo de alunos e pais no ensino médio. São Paulo: Fundação Carlos Chagas (Textos F.C.C., n. 25).

ZIBAS, D. M. L., KRAWCZYK, N., (2005). Acompanhamento e avaliação interativa da implantação das novas políticas de gestão do ensino médio. Relatório de pesquisa. São Paulo: Fundação Carlos Chagas.

Recebido em novembro de 2004 Aprovado em janeiro de 2005 


\title{
Resumos/Abstracts
}

\author{
Dagmar M. L. Zibas
}

A reforma do ensino médio nos anos de 1990: o parto da montanha e as novas perspectivas

O artigo descreve algumas injunções sociais, econômicas e pedagógicas que, ao final dos anos de 1990, estavam exigindo uma reforma curricular do ensino médio. Faz um levantamento da repercussão, na academia, dos documentos do Conselho Nacional de Educação que veicularam a reforma de 1998. Discute os dados de três pesquisas que acompanharam ou fizeram uma avaliação inicial da interação entre a reforma e as escolas, apontando indícios quanto à falta de condições mínimas necessárias para a consecução dos objetivos oficialmente propostos. Finaliza questionando as atuais perspectivas para uma reforma do ensino médio que realmente favoreça o desenvolvimento integral da maioria dos alunos das escolas públicas.

Palavras-chave: ensino médio; reforma curricular; políticas para o ensino médio

\section{The reform of secondary education in the 90's: the mountain birth and new perspectives}

The article describes some of the social, economic and pedagogic injunctions that had been demanding a curricular reform in secondary education, in the end of the 90's. It discusses the impact upon the academic community of the documents of the National Council of Education concerning the reform of 1998. It also discusses data from three research studies that both kept track and initially evaluated the interaction between the reform and the schools. It argues that there has been a lack of minimal conditions that would be required to attain the officially proposed reform aims. It concludes problematising the current perspectives towards secondary education reform, bearing in mind it should truly promote a thorough development of most pupils within public schools.

Key-words: secondary education; curricular reform; secondary education policies 